\title{
Diagnostic Accuracy of Seismocardiography Compared with Electrocardiography for the Anatomic and Physiologic Diagnosis of Coronary Artery Disease During Exercise Testing
}

\author{
Richard A. Wilson, MD, Virinderjit S. Bamrah, MD, Joseph Lindsay, Jr., MD, \\ Markus Schwaiger, MD, and Joel Morganroth, MD
}

\begin{abstract}
A multicenter study was performed to compare the diagnostic accuracy of a new technique, seismocardiography, with that of electrocardiography for physiologically and anatomically significant ischemic coronary artery disease (CAD) during exercise stress testing.

Five participating centers enrolled 129
\end{abstract} patients who had simultaneous seismocardiograms and 12-lead electrocardiograms at the time of their exercise treadmill stress tests. Two different definitions of CAD were used: anatomic and physiologically significant disease. The presence of anatomically significant CAD ( $\geq 50 \%$ diameter stenosis) was documented by coronary angiography. Physiologically significant CAD was defined as present in the same 129 patients when coronary arteriography ( $\geq 50 \%$ diameter stenosis) and thallium-201 scintigraphy (defect on initial postexercise images) were both abnormal. Seismocardiography had a significantly better sensitivity for detecting anatomic CAD than did electrocardiography (73 vs $48 \%$; $p<0.001$ ), without loss of specificity (78 vs $80 \% ; p=N S$ ). Exercise seismocardiography added significant incremental diagnostic information beyond that provided by exercise electrocardiography. Seismocardiography was more sensitive (without less specificity) in women and in patients who did not achieve maximal predicted heart rate. In patients with physiologically significant CAD, the seismocardiogram was also significantly more sensitive (78\%) than was the electrocardiogram (55\%) (p $<0.02$ ), without loss of specificity (84 vs $74 \%$ ).

Seismocardiography significantly improved sensitivity for the detection of anatomic and

From the Cardiology Division, Oregon Health Sciences University, Portland, Oregon; Cardiology Division, Medical College of Wisconsin, Milwaukee, Wisconsin; Cardiology Division, Washington Hospital Center, George Washington University, Washington, D.C.; Cardiology Division, University of Michigan Medical Center, Ann Arbor, Michigan; and Cardiology Division, Graduate Hospital, Philadelphia, Pennsylvania. This study was supported in part by a grant from Seismed Instruments Incorporated, Minneapolis, Minnesota. Manuscript received September 1, 1992; revised manuscript received and accepted September 21, 1992.

Address for reprints: Richard A. Wilson, MD, Division of Cardiology, L462, Oregon Health Sciences University, 3181 S.W. Sam Jackson Park Road, Portland, Oregon 97201-3098. physiologic CAD. It is easy to perform and may be a clinically useful adjunct in exercise stress testing.

(Am J Cardiol 1993;71:536-545)

$\mathrm{T}$ The use of electrocardiography during exercise stress testing for the noninvasive diagnosis of coronary artery disease (CAD) has a relatively low sensitivity (approximately 68\%), ${ }^{1,2}$ Other noninvasive tests such as thallium or radionuclide ventriculography ${ }^{3,4}$ and stress echocardiography ${ }^{5}$ have been shown to have greater sensitivity for detecting CAD, but are more expensive and need additional expertise. Thus, an initial test for CAD, which has improved sensitivity, and is also safe and inexpensive, and easy to perform and interpret, would be of significant clinical value in the primary care setting. Seismocardiography is a new noninvasive technique that measures seismic waves on the anterior chest surface emanating from the motion of the heart. ${ }^{6}$ Changes in cardiac wall motion induced by ischemia with exercise or balloon inflation during percutaneous transluminal coronary angioplasty can be detected by this methodology. ${ }^{6,7}$ Seismocardiography can be classified as a form of displacement cardiography that includes apexcardiography, ${ }^{8}$ kinetocardiography, ${ }^{9}$ ballistocardiography ${ }^{10,11}$ and cardiokymography. ${ }^{12,13}$ Seismocardiography is known to be safe, inexpensive and easy to perform, but its sensitivity for detecting patients with CAD needs to be validated. The purpose of this multicenter study was to evaluate the ability of seismocardiography to augment the sensitivity and specificity of cxcrcisc electrocardiography for the diagnosis of ischemic CAD in a large group of patients with and without CAD. The incremental diagnostic information provided by exercise seismocardiography beyond exercise electrocardiography and clinical variables was evaluated. In this study, a purely anatomic definition (i.e., angiographic criterion alone), as well as a physiologic one (angiographic plus thallium-201 scintigraphic criteria), of $\mathrm{CAD}$ was used to evaluate the diagnostic accuracy of seismocardiography.

\section{METHODS}

Patients were recruited from 5 participating institutions from August 1989 to January 1991 after approvals of the study by the appropriate institutional review 
boards. There were 611 patients who had exercise electrocardiography and thallium imaging for clinical reasons. Exercise seismocardiography was performed in conjunction with the aforementioned tests, but only for the purpose of this study.

Of 611 patients, 169 were enrolled based on the criterion of a coronary angiogram within 3 months, before or after, of their exercise stress test. The 442 patients who were not eligible for inclusion in this study were excluded for absence of a coronary angiogram or for having an angiogram that did not fulfill study criteria. If a coronary angiogram was performed within the previous 3 months, and no significant changes in cardiac symptoms occurred between the exercise thallium test and angiogram, then it was used for comparison with the exercise test results. If myocardial infarction or bypass surgery had occurred between the 2 tests, the patient was excluded. Patients who had coronary angioplasty were excluded if the angioplasly was performed $<3$ months before the stress test. If angioplasty was performed 3 to 6 months before the exercise test, then an angiogram obtained within 2 weeks of the exercise test was needed for inclusion in the study. Patients without prior coronary angiograms were followed by telephone at 1 and 3 months after the exercise test to determine if an angiogram had been obtained after the exercise test.

Of 169 patients with angiograms, 16 were excluded before seismocardiographic or electrocardiographic interpretation for not fulfilling entry criteria. The protocoldefined exclusion criteria were as follows: intraventricular conduction delay (right or left bundle branch block) on the electrocardiogram $(n=7)$; myocardial infarction within 6 weeks of exercise stress test $(n=3)$; atrial fibrillation $(\mathrm{n}=3)$; premature ventricular contractions or intermittent ventricular pacing, or both $(\mathbf{n}=2)$; heart transplantation $(\mathrm{n}=1)$; signiticant valvular heart disease $(n=0)$; and prior coronary artery bypass surgery $(n=0)$. Of the remaining 153 patients, angiographic $(n=13)$, thallium-201 scintigraphic $(n=2)$, electrocardiographic $(\mathrm{n}=0)$ or seismocardiographic $(\mathrm{n}=9)$ data were unavailable or inadequate for evaluation in 24 patients ( 2 patients had 2 reasons for exclusion).
The remaining 129 patients had complete data including coronary angiography, exercise thallium-201 scintigraphy, and exercise electrocardiography and seismocardiography. A subset of this group $(n=9)$ initially had "normal" coronary angiograms and were later (within 3 months) recruited to undergo exercise thalliun-201 (and seismocardiographic) stress testing solely for the purpose of this study. The other patients all had clinically indicated exercise tests; angiograms were obtained before the exercise tests in 69 patients and after the exercise tests in 60 . Group A included 89 patients with $\geq 50 \%$ diameter coronary artery stenoses on angiography, and group B included 40 patients with $<50 \%$ stenoses.

Exercise electrocardiography: Resting supine and upright 12-lead electrocardiograms were obtained immediately before a symptom-limited exercise treadmill test that used either the Naughton $(n=17)$, Bruce $(\mathbf{n}=99)$ or other $(n=13)$ prolocol. ${ }^{11}$ Exercise was stopped for $>2 \mathrm{~mm}$ of ST depression ( $\mathrm{n}=11$ ), a $20 \mathrm{~mm}$ $\mathrm{Hg}$ decrease in systolic blood pressure $(n=1)$, systolic blood pressure $>220 \mathrm{~mm} \mathrm{Hg}(\mathrm{n}=7)$, chest pain $(n=37)$, fatigue $(n=37)$ or $\geq 85 \%$ age-predicted maximal heart rate achieved $(n=36)$. Electrocardiographic evidence of ischemia was defined as $\geq 1 \mathrm{~mm}$ of horizontal or downsloping ST-segment depression from the baseline ST segment as visually estimated 60 to $80 \mathrm{~ms}$ after the J point.

Exercise seismocardiography: The method of obtaining rest and immediate postexercise seismocardiograms was previously reported in detail. ${ }^{6}$ Briefly, a $1 \mathrm{~kg}$ ultralow-frequency piezoelectric acceleration transducer (Seismed Instruments Incorporated, Minneapolis, MN) was positioned on the sternum in the midline, with the lower edge of the accelerometer at the xyphoid process, with the patient in the supine position. A 1-minute recording was obtained. A 3-lead electrocardiogram was recorded simultaneously to provide a fiducial mark for signal averaging and the proper timing of the recorded seismic waves induced by cardiac motion transmitted to the anterior chest wall. The seismic waveforms underwent band-pass filtering and analog-to-digital conversion (sample rate 250/s), as well as signal processing and

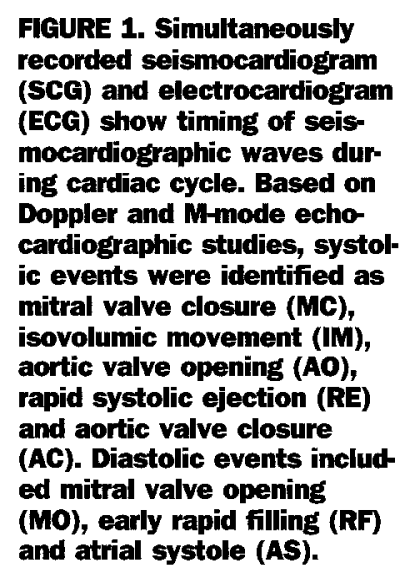

FIGURE 1. Simultaneously recorded seismocardiogram (SCG) and electrocardiogram (ECG) show timing of seismocardiographic waves during cardiac cycle. Based on Doppler and M-mode echocardiographic studies, systolic events were identified as mitral valve closure (MC) isovolumic movement (IM), alve opening (AO), and aortic valve closure (AC). Diastolic events included mitral valve opening and atrial systole (AS).

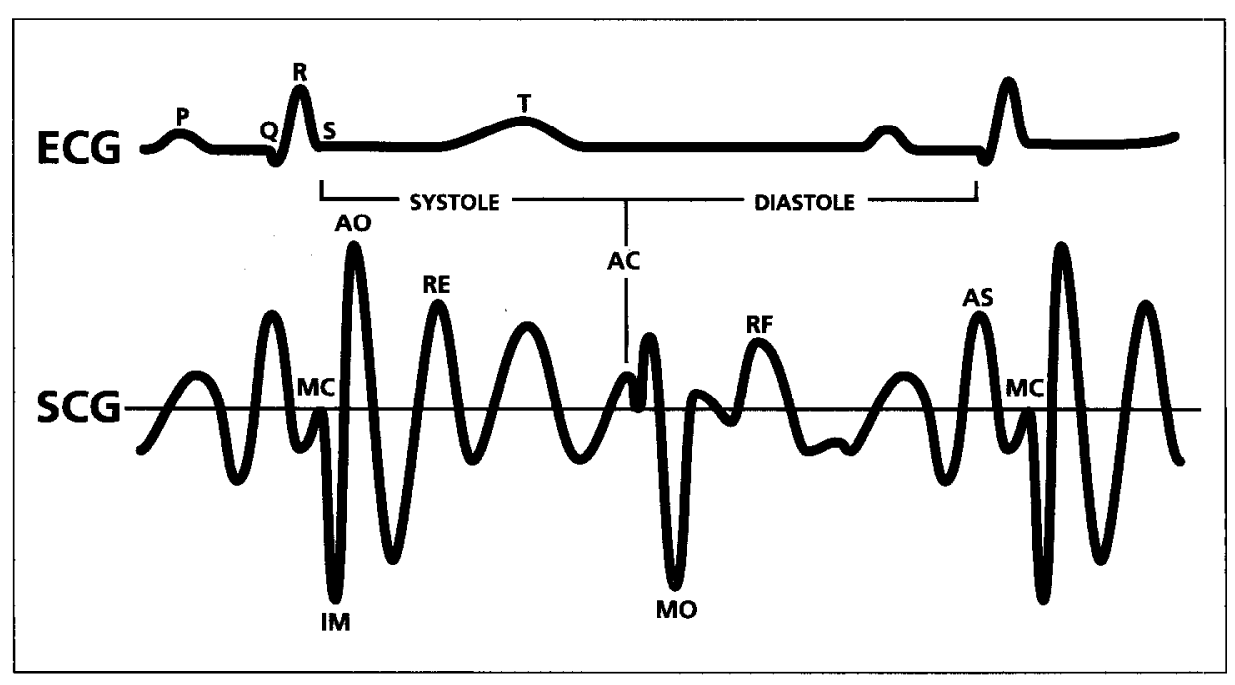




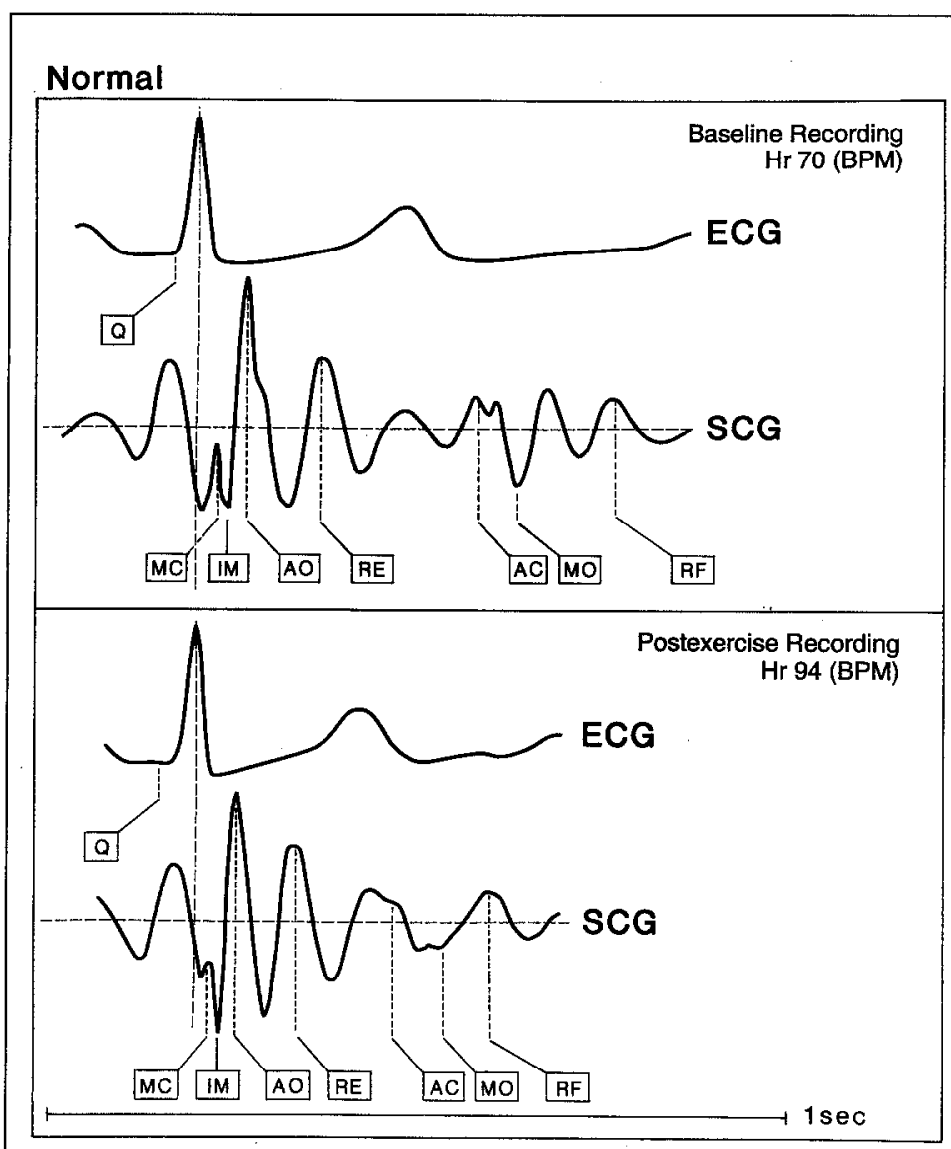

\section{Abnormal}

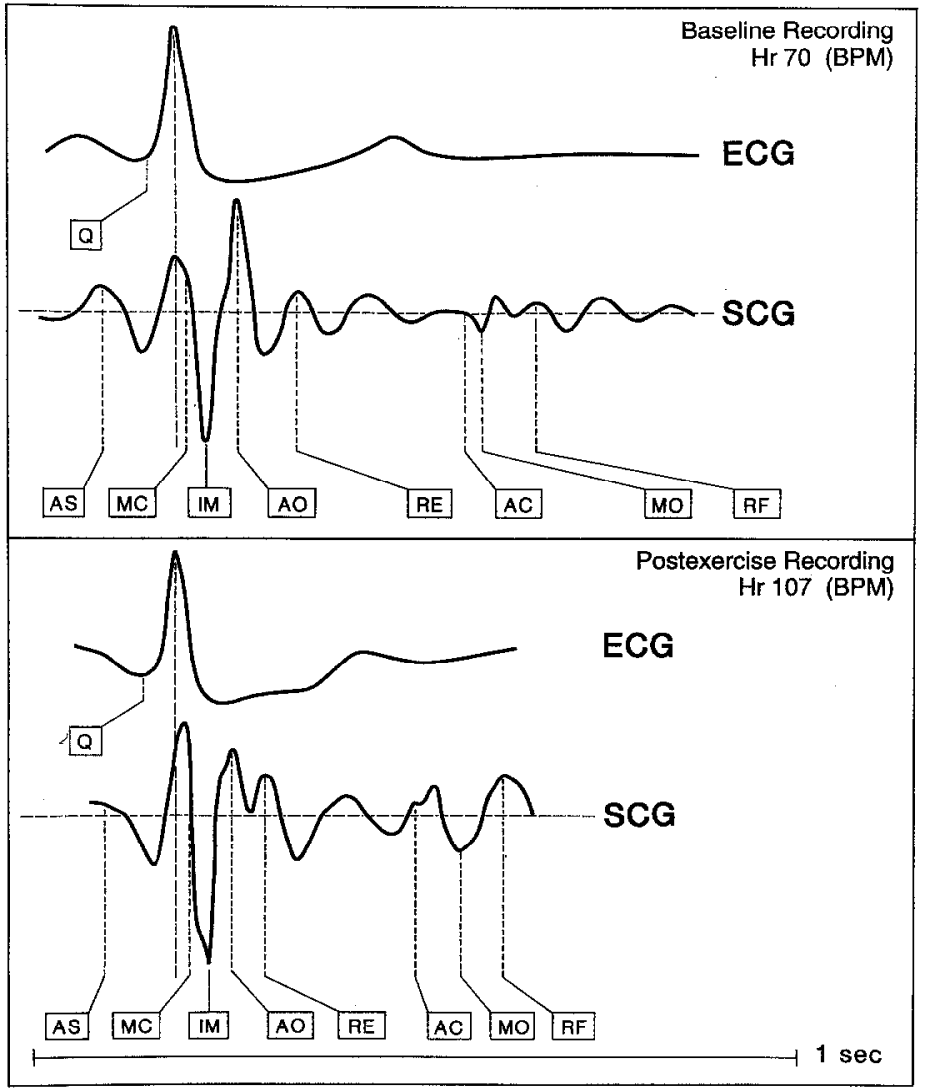

FICURE 2 Resting and postexercise seismocardiograms (SCG) and matching electrocardiograms (ECG) in 2 patients; 1 with normal coronary arteries and "nomal" SCG showing no significant changes in SCG waveform momhology from baseline to after exercise, and the other with $>90 \%$ stenosis of left anterior descending coronary artery and positive SCG showing significant changes in SCG waveform morphology. Postexercise SCG shows decrease in aortic valve opening (AO) amplitude and increase in early rapid filling (RF) amplitude compared with baseline SCG. Other abbreviations as in Figure 1. 
averaging. The data were then stored on a microprocessor for later analysis and a hard copy output of results. The real-time seismocardiographic and electrocardiographic tracings appeared on the computer screen during data acquisition to ensure technically proper recordings. Immediately after the exercise test, the patient was again placed in the supine position, and a second 1-minute seismocardiogram was recorded. A third 1minute seismocardiogram was also obtained after $\geq 5$ minutes of recovery after exercise. For this study, the recovery seismocardiogram was obtained 30 minutes after exercise to avoid delays in thallium imaging.

Previous work using simultaneous M-mode, 2-dimensional and Doppler echocardiography documented the correspondence of seismocardiographic waves with intracardiac events, ${ }^{6,7}$ including mitral valve closure, aortic valve opening, rapid left ventricular ejection, peak left ventricular outflow tract velocity, aortic valve closure, mitral valve opening, early rapid filling and atrial systole (Figure 1).

An example from this study of the change in seismocardiographic waveforms with exercise-induced ischemia is shown in Figure 2. The major criterion for abnormality was a relative change in the systolic portion of the tracing. The amplitude and timing of the pre-exercise aortic valve opening point was compared with those of the immediate postexercise aortic valve opening point. $\mathrm{A} \geq 50 \%$ decrease or disappearance in this point in the postexercise waveform compared within the pre-exercise waveform was considered abnormal. If with a 10 beats/min increase in heart rate after exercise the duration of $\mathrm{Q}$ wave to aortic valve opening did not decrease, the test was considered abnormal. A secondary criterion for the presence of coronary ischemia was an increase in the amplitude of the diastolic RF wave immediately after exercise. If the overall morphology of the waveform was unchanged but the frequency of the waves increased due to increased heart rate, the tracing was considered normal. The interpretation criteria were previously described. ${ }^{15}$ Registration of waves for proportional changes in heart rate was previously validated. ${ }^{6}$ In a previous study, inter- and intraobserver agreement were 80 and $88 \%$, respectively. ${ }^{15}$ The reproducibility of the baseline seismocardiogram over a 3-month period has been validated. ${ }^{6}$

Thallium-201 scintigraphy: At peak exercise, $3 \mathrm{mCi}$ (111 MBq) of thallium-201 was injected intravenously, and exercise was continued for 30 to 60 seconds. Single-photon emission computed tomographic (SPECT) imaging was begun 10 to 15 minutes after excrcisc. Image acquisition was performed over $180^{\circ}$, from the $30^{\circ}$ right anterior oblique to $60^{\circ}$ left posterior oblique projection, with 32 stops of 30 seconds each. Delayed images were obtained 3 to 4 hours after exercise. Immediate postexercise tomographic images were interpreted semiquantitatively using a 5-point scale as follows: $0=$ normal; $1=$ equivocal defect; $2=$ moderate defect; $3=$ severe defect; and $4=$ no perfusion. Thallium-201 redistribution was graded on a 4-point scale as follows: $0=$ no redistribution; $1=$ minimal redistribution; $2=$ partial redistribution; and $3=$ complete redistribution. In 11 patients, reinjection of thallium (1
$\mathrm{mCi}[37 \mathrm{MBq}]$ ) was performed before the acquisition of delayed images.

Coronary angiography: Coronary angiography was performed using the Judkins technique. Reduction in percent luminal diameter was visually assessed, and categorized as 0 to $25 \%, 26$ to $49 \%, 50$ to $69 \%, 70$ to $89 \%$, 90 to $99 \%$, and $100 \%$.

Test interpretation: Electrocardiograms, seismocardiograms, thallium images and coronary angiograms were all interpreted without knowledge of clinical findings or other test results by 2 independent observers (see Appendix). A third independent observer adjudicated any differences between readers.

Clinical data: Before the excrcise test, a medical history concerning prior myocardial infarction, prior angiography, other cardiac events and cardiac medications was obtained from the patient. Cardiac risk factors were also assessed by patient history (smoking, hypertension, hypercholesterolemia, diabetes and chest pain). Pretest symptoms were classified by the examining physician as either noncardiac, or atypical or typical angina. There were 25 patients who were asymptomatic, 16 with noncardiac symptoms, 22 with atypical angina and 66 with typical angina.

The pretest likelihood of CAD was estimated using the Framingham Prospective Risk Score, ${ }^{16}$ translated from 6-year future risk to present risk. . $^{7,18}$

Data analysis: Anatomically significant $\mathrm{CAD}$ was defined based on the angiographic criterion of the presence of $\geq 50 \%$ diameter stenosis in $\geq 1$ epicardial artery or major branch.

An alternative definition of significant $C A D$ was also used in the comparison of the electrocardiogram and seismocardiogram. Physiologically significant disease was considered present if the patient had both a thallium defect and $\geq 50 \%$ luminal diameter stenosis on angiography $(n=51)$. Physiologically significant disease was considered absent if the patient had neither a thallium defect nor $<50 \%$ diameter stenosis on angiography $(n=31)$. Patients who had thallium scintigraphic and coronary angiographic results that did not agree were omitted from this analysis $(n=47)$. Using slightly different criteria for evidence of significant ischemia, a group of 70 patients was identified who had both $\geq 50 \%$ diameter coronary stenosis on angiography and a reversible thallium defect $(n=33)$, or neither $(n=37)$. Patients who had thallium scintigraphic and coronary arteriographic results that did not agree were omitted from this analysis $(n=59)$. This group $(n=70)$ was designated the "physiologically ischemic" group. The diagnostic accuracy of the electrocardiogram and seismocardiogram using these anatomic and physiologic alternative criteria for $\mathrm{CAD}$ was assessed by comparison of sensitivity, specificity, and positive and negative predictive accuracy.

Receiver-operating characteristic curves were constructed from logistic models. Model 1 contained age, gender and angina symptoms before testing. Model 2 contained the aforementioned variables and the results of the exercise electrocardiogram; model 3 added the results of the exercise seismocardiogram. The differences in the areas under the curves for each model were 
compared by the method of Hanley and $\mathrm{McNeil}^{19}$ to assess the ability of the logistic models to accurately predict anatomic CAD. ${ }^{20}$

Differences between groups for electrocardiographic and seismocardiographic sensitivity and specificity were compared by the test for proportions. Differences within groups comparing electrocardiographic and seismocardiographic sensitivity and specificity were compared by McNemar's test. Comparisons of predictive values were performed by chi-square analysis. A p value $\leq 0.05$ with 2-sided testing was considered significant. Data are expressed as mean $\pm \mathrm{SE}$.

\section{RESULTS}

Clinical characteristics: The baseline characteristics of all 129 patients, as well as for groups A and B, are listed in Table I. Only $2 \%$ of patients were receiving digoxin at the time of the exercise test. Antianginal medications were not routinely discontinued for the exercise test. The mean maximal heart rate achieved dur- ing exercise averaged $85 \%$ of the age-predicted maximal heart rate. Three patients in group B had history of myocardial infarction, 2 of whom had subsequent angioplasty. The 10 patients in group B categorized as having prior known CAD included the 3 with prior myocardial infarction, as well as 7 who had coronary angiography with evidence of mild disease $(<50 \%$ stenosis) before exercise testing.

Anatomically significant disease: Overall sensitivity and specificity, as well as positive and negative predictive values, for anatomically significant disease are listed in Table II. The sensitivity of the seismocardiogram was significantly higher than that for the clectrocardiogram. Specificity was not significantly different between the tests.

Because the seismocardiogram and electrocardiogram were both obtained from the same exercise test, the predictive value of concordance of the 2 test results was evaluated. The seismocardiogram and electrocardiogram had concordant results in 78 of 129 patients

\begin{tabular}{|c|c|c|c|}
\hline & $\begin{array}{l}\text { All Patients } \\
(n=129)\end{array}$ & $\begin{array}{l}\text { Group A } \\
(n=89)\end{array}$ & $\begin{array}{l}\text { Group B } \\
(n=40)\end{array}$ \\
\hline$\geq 50 \%$ lesions by angiography & 89 & 89 & 0 \\
\hline Age (year; mean $\pm S E$ ) & $57 \pm 2$ & $59 \pm 2$ & $53 \pm 2$ \\
\hline Maximum/minimum & $84 / 27$ & $84 / 28$ & $82 / 27$ \\
\hline Men & $96(74)$ & $68(76)$ & $28(70)$ \\
\hline Women & $33(26)$ & $21(24)$ & $12(30)$ \\
\hline Previous myocardial infarction & $31(21)$ & $28(31)$ & $3(8)$ \\
\hline Prior known coronary artery disease & $68(53)$ & $58(65)$ & $10(25)$ \\
\hline Prior angiography & $64(50)$ & $54(61)$ & $10(25)$ \\
\hline Prior coronary angioplasty & $17(13)$ & $15(17)$ & $2(5)$ \\
\hline Systemic hypertension & $65(50)$ & $43(48)$ & $22(55)$ \\
\hline Current cigarette smokers & $37(29)$ & $27(30)$ & $10(25)$ \\
\hline History of smoking & $25(19)$ & $19(21)$ & $6(15)$ \\
\hline Hypercholesterolemia & $52(40)$ & $42(47)$ & $10(25)$ \\
\hline Chronic lung disease & $7(5)$ & $0(0)$ & $7(18)$ \\
\hline Diabetes & $27(20)$ & $20(22)$ & $7(18)$ \\
\hline Juvenile onset & $9(7)$ & $6(7)$ & $3(8)$ \\
\hline Adult onset & $18(14)$ & $14(16)$ & $4(10)$ \\
\hline Valvular disease & $7(5)$ & $5(6)$ & $2(5)$ \\
\hline Cardiomyopathy & $2(2)$ & $1(1)$ & $1(3)$ \\
\hline Congestive heart failure & $3(2)$ & $3(3)$ & $0(0)$ \\
\hline Digoxin & $3(2)$ & $3(3)$ & $0(0)$ \\
\hline$\beta$-adrenergic blockers & $40(31)$ & $29(33)$ & $11(28)$ \\
\hline Calcium antagonists & $64(50)$ & $45(51)$ & $19(48)$ \\
\hline Nitrates & $41(32)$ & $33(37)$ & $8(20)$ \\
\hline $\begin{array}{l}\text { Exercise duration } \\
\qquad(\text { min; mean } \pm 1 \mathrm{SE})\end{array}$ & $8.0 \pm 0.3^{*}$ & $7.0 \pm 0.3 \uparrow$ & $9.0 \pm 0.5 \ddagger$ \\
\hline Maximum/minimum & $20 / 2$ & $20 / 2$ & $19 / 4$ \\
\hline $\begin{array}{l}\text { Maximal heart rate (beats/min; } \\
\text { mean } \pm 1 \mathrm{SE} \text { ) }\end{array}$ & $139 \pm 2$ & $134 \pm 2$ & $150 \pm 3$ \\
\hline Maximum/minimum & $185 / 77$ & $172 / 77$ & $: \quad 185 / 100$ \\
\hline $\begin{array}{l}\text { Postexercise SCG HR (beats/min; } \\
\text { mean } \pm 1 \text { SE) }\end{array}$ & $95 \pm 2$ & $92 \pm 2$ & $103 \pm 3$ \\
\hline Maximum/minimum & $140 / 47$ & $132 / 47$ & $140 / 61$ \\
\hline $\begin{array}{l}\text { Peak systolic } \mathrm{BP}(\mathrm{mm} \mathrm{Hg} \\
\text { mean } \pm 1 \mathrm{SE})\end{array}$ & $177 \pm 2$ & $176 \pm 3$ & $179 \pm 4$ \\
\hline Maximum/minimum & $247 / 100$ & $247 / 109$ & $230 / 100$ \\
\hline $\begin{array}{l}\text { Pressure-rate product } \\
\quad \text { (mean } \pm 1 \mathrm{SE})\end{array}$ & $24,723 \pm 503$ & $23,670 \pm 594$ & $27,067 \pm 836$ \\
\hline Maximum/minimum & $38,779 / 10,241$ & $38,779 / 10,241$ & $37,000 / 11,000$ \\
\hline \multicolumn{4}{|c|}{$\begin{array}{l}\text { *Data for } 99 \text { patients with Bruce protocol; †data for } 65 \text { patients with Bruce protocol; } \neq \text { data for } 34 \text { patients with Brucc } \\
\text { protocol. } \\
\text { Numbers in parentheses are percents of total group. } \\
\mathrm{BP}=\text { blood pressure; } \mathrm{HR}=\text { heart rate; } \mathrm{SCG}=\text { seismocardiographic. }\end{array}$} \\
\hline
\end{tabular}




\begin{tabular}{|c|c|c|c|c|}
\hline & $\begin{array}{l}\text { Sensitivity } \\
\text { (1 SE) }\end{array}$ & $\begin{array}{l}\text { Specificity } \\
\text { (1 SE) }\end{array}$ & $\begin{array}{l}\text { Positive } \\
\text { Predictive } \\
\text { Value } \\
\text { (1 SE) }\end{array}$ & $\begin{array}{l}\text { Negative } \\
\text { Predictive } \\
\text { Value } \\
\text { (1 SE) }\end{array}$ \\
\hline \multicolumn{5}{|c|}{ Group A and B patients ( $\mathrm{n}=129$ ) } \\
\hline Electrocardiography & $0.48(0.05)$ & $0.80(0.06)$ & $0.84(0.05)$ & $0.41(0.06)$ \\
\hline Seismocardiography & $0.73(0.05)$ & $0.78(0.07)$ & $0.88(0.04)$ & $0.56(0.07)$ \\
\hline$p$ value & 0.001 & 1.00 & 0.77 & 0.12 \\
\hline
\end{tabular}

$(60 \%)$. In these patients, the positive and negative predictive accuracies of the concordant test results were 92 and $63 \%$, respectively. These were not significantly better than the positive and negative predictive accuracies for the seismocardiogram alone (88 and $56 \%$, respectively), or the positive predictive accuracy of the electrocardiogram alone (84\%). The negative predictive accuracy of the electrocardiogram alone $(41 \%)$ was significantly lower than if there was concordance of negative seismocardiograms and electrocardiograms $(63 \% ; \mathrm{p}=$ 0.01 ).

Using the differences in the areas under the receiver-operating characteristic curves, constructed from logistic model 1 (age, gender and pretest angina symptoms), model 2 (model 1 and exercise electrocardiographic results), and model 3 (model 2 and exercise seismocardiographic results), it was possible to evaluate the additive effect of the exercise tests on diagnostic accuracy. The area under the curve was $70.3 \pm 4.7 \%$ for model $1,74.9 \pm 4.1 \%$ for model 2 , and $85.1 \pm 3.3 \%$ for model 3 (Figure 3 ). There was a significant increase in the area from model 1 compared with from model 2 $(p=0.0004)$, and from model 2 compared with from model $3(\mathrm{p}=0.00001)$. For model 3 , stepwise logistic regression resulted in coefficients of 2.277 for seismocardiography, 0.968 for electrocardiography, -0.853 for sex, 0.503 for angina symptoms, and 0.030 for gender.

Physiologically significant disease: A separate analysis was performed using criteria for the presence of physiologically significant disease based on concordance of angiography and any defect (fixed or reversible) on thallium scintigraphy. For these patients $(n=82)$, sensitivity and specificity, as well as the positive and negative predictive accuracies, for the seismocardiogram and electrocardiogram are listed in Table III. The sensitivity of the seismocardiogram was significantly greater than that of the electrocardiogram. The specificity, and positive and negative prediclive values were not significantly different between the 2 tests.

In the physiologically significant disease group, the seismocardiogram and electrocardiogram were concordant in $65 \%$ (53 of 82) of patients. The positive and negative predictive values of the concordant seismocardiograms and electrocardiograms were 88 and $78 \%$, respectively. The $78 \%$ negative predictive value was significantly better than for the electrocardiogram alone $(50 \% ; \mathrm{p}=0.01)$, but not for the seismocardiogram alone $(70 \%)$. Positive predictive value was not significantly
FGURE 3. Receiver-operating characteristic curve (ROC) areas for models 1 (age, gender and angina status), 2 (age, gender, angina status and exercise electrocardiographic results) and 3 (age, gender, angina status, and exercise electrocardio graphic and seismocardiographic results). Each bar represents mean value of diagnostic power and associated SE.

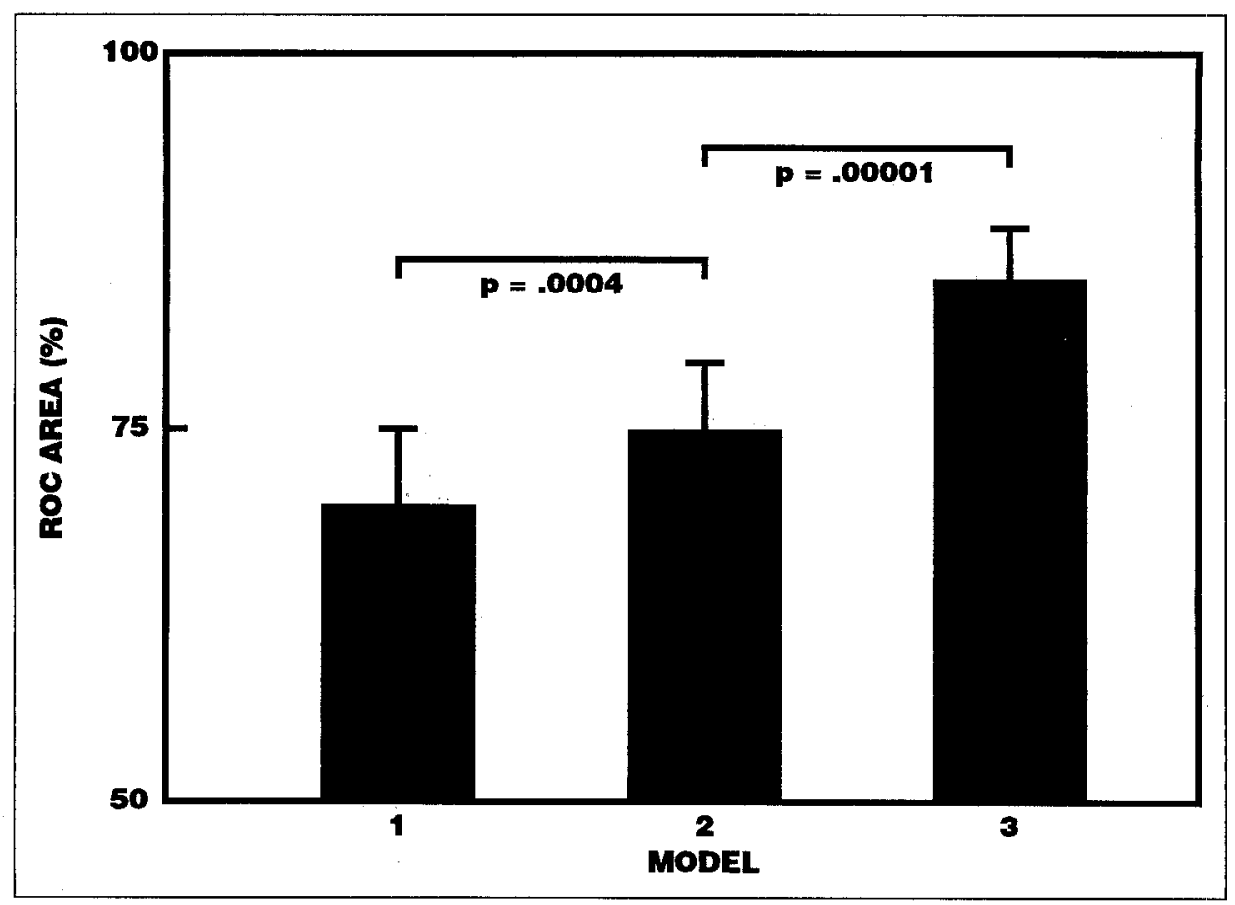


different for either the electrocardiogram $(78 \%)$ or seismocardiogram (89\%) alone.

In the physiologically ischemic group $(n=70)$, based on agreement of angiography and a reversible thallium scintigraphy defect, the electrocardiographic sensitivity tended to be less than the seismocardiographic sensitivity $(\mathrm{p}=0.10)$. Specificity, and positive and negative predictive values for the 2 tests were not significantly different. However, the electrocardiographic values were less than the seismocardiographic values, and absence of statistical significance may be due to the small sample size.

In the $69 \%$ (48 of 70 ) of physiologically ischemic patients who had concordant seismocardiograms and electrocardiograms, positive predictive value $(86 \%)$ was not significantly greater than for the seismocardiogram $(80 \%)$ or electrocardiogram $(72 \%)$ alone. However, the predictive value of a concordant negative test result (93\%) was significantly greater than that of the electrocardiogram alone $(71 \% ; \mathrm{p}=0.01)$, but not that of the seismocardiogram alone (86\%).

Extent and severity of disease: There was no loss of sensitivity for the seismocardiogram in 31 patients with only 1-vessel disease (74\%) compared with that in the 58 with multivessel disease $(72 \%)$. Electrocardiographic sensitivity was $48 \%$ for both single and multivessel disease:

Patients undergoing coronary angiography were categorized according to the percent luminal diameter stenoses criteria of: (1) $<$ or $\geq 50 \%$, or $(2)<$ or $\geq 70 \%$. The sensitivity of the seismocardiogram was greater than that of the electrocardiogram for the 2 categories of percent stenosis (73 vs $48 \%[p=0.001]$, and 74 vs $51 \%$ $[p=0.002]$, respectively). Neither seismocardiographic nor electrocardiographic sensitivity changed in the 2 stenosis categories. Specificity of the seismocardiogram was not significantly different from that of the electrocardiogram for either the $50 \%$ ( 78 vs $80 \%$ ) or $70 \%$ (71 vs $79 \%$ ) stenosis criterion.

Clinical subgroups: An analysis of clinical subgroups for a comparison of the sensitivity and specificity of the seismocardiogram and electrocardiogram is presented in Table IV. The detection of $\geq 50 \%$ coronary narrowing was used for this analysis. The seismocardiogram was more sensitive than was the electrocardiogram in both men and women. Seismocardiographic sensitivity was greater than electrocardiographic sensitivity in patients with $\beta$ blockade or calcium antagonist medica-

\begin{tabular}{|c|c|c|c|c|}
\hline & $\begin{array}{l}\text { Sensitivity } \\
\text { (1 SE) }\end{array}$ & $\begin{array}{l}\text { Specificity } \\
\text { (1 SE) }\end{array}$ & $\begin{array}{c}\text { Positive } \\
\text { Predictive } \\
\text { Value (I SE) }\end{array}$ & $\begin{array}{l}\text { Negative } \\
\text { Predictive } \\
\text { Value } \\
\text { (1 SE) }\end{array}$ \\
\hline \multicolumn{5}{|c|}{ Physiologically significant disease $(n=82)$} \\
\hline Electrocardiography & $0.55(0.07)$ & $0.74(0.08)$ & $0.78(0.07)$ & $0.50(0.07)$ \\
\hline Seismocardiography & $0.78(0.06)$ & $0.84(0.07)$ & $0.89(0.05)$ & $0.70(0.08)$ \\
\hline$p$ value & 0.02 & 0.45 & 0.29 & 0.10 \\
\hline \multicolumn{5}{|c|}{ Physiologically ischennic disease $(n=70)$} \\
\hline Electrocardiography & $0.64(0.08)$ & $0.78(0.07)$ & $0.72(0.08)$ & $0.71(0.07)$ \\
\hline Seismocardiography & $0.85(0.06)$ & $0.81(0.06)$ & $0.80(0.07)$ & $0.86(0.06)$ \\
\hline$p$ value & 0.10 & 1.00 & 0.67 & 0.20 \\
\hline
\end{tabular}

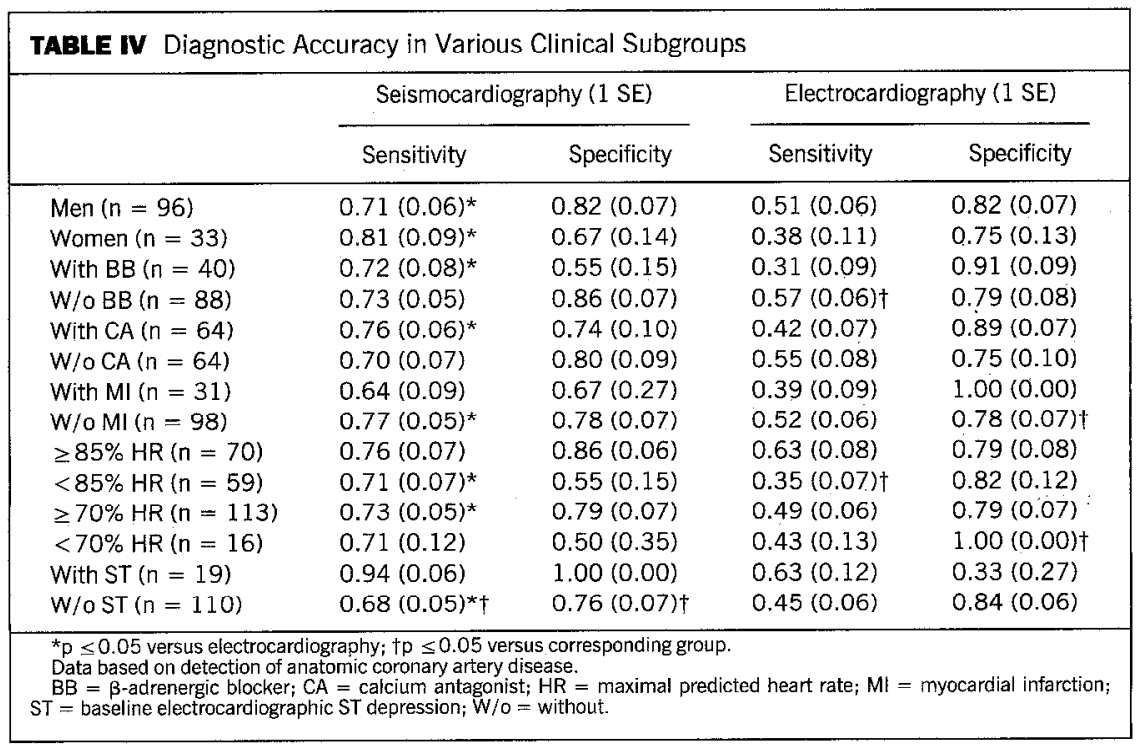


tion. The sensitivity was greater for the seismocardiogram than for the electrocardiogram in the absence of prior myocardial infarction.

Seismocardiographic sensitivity, although not statistically significant, tended to be greater than electrocardiographic sensitivity when patients exercised to $85 \%$ age-predicted maximal heart rate. However, electrocardiographic sensitivity was significantly less than seismocardiographic sensitivity in the $<85 \%$ maximal heart rate group $(\mathrm{p}<0.001)$. Specificity was not different between the seismocardiogram and electrocardiogram in the $\geq$ and $<85 \%$ maximal heart rate groups. In the $<70 \%$ maximal heart rate group, sensitivity of the seismocardiogram was not significantly different from that in the $\geq 70 \%$ maximal heart rate group. In contrast, electrocardiographic sensitivity was low in both groups.

Patients without ST depression on baseline resting electrocardiograms had significantly greater seismocardiographic sensitivity than electrocardiographic sensitivity. Seismocardiographic sensitivity and specificity for patients without baseline ST depression was less than those for patients with ST depression on the pre-exercise tracing. Electrocardiographic specificity was not significantly different between the groups with and without baseline ST depression.

Pretest likelihood of coronary artery disease: In the group of patients with a pretest probability for CAD of 20 to $79 \% \quad(n=39)$, the clinical value of the seismocardiogram was compared with that of the electrocardiogram. For detection of $\geq 50 \%$ coronary artery narrowing in this subgroup of patients at moderate risk of $\mathrm{CAD}$, the seismocardiogram had a significantly greater sensitivity than did the electrocardiogram (70 vs 33\%; $\mathrm{p}=0.02$ ). Negative predictive value (56 and $38 \%$ ), specificity ( 83 and $92 \%$ ) and positive predictive accuracy (90 and 90\%) were all similar for the seismocardiogram and electrocardiogram, respectively.

Postexercise seismocardiogram timing: The effect of timing of the postexercise seismocardiographic recording was evaluated in 109 patients in whom timing data were available. For detection of $\geq 50 \%$ coronary artery narrowing, the sensitivity, specificity, and positive and negative predictive accuracies were calculated for the various time intervals after exercise. There were no significant differences in sensitivity when early ( 0 to 89 seconds) $(n=77)$ or delayed (90 to 217 seconds) $(n=32)$ recordings were obtained ( 72 and $87 \%$, respectively; $\mathrm{p}=0.15$ ).

\section{DISCUSSION}

The major finding of this study confirms an earlier report that seismocardiography significantly improves the sensitivity of exercise testing for detection of CAD compared with electrocardiography, without a loss of specificity. ${ }^{15}$ Exercise electrocardiography improves diagnostic precision by $5 \%$ more than the pretest estimate available from age, gender, and anginal status by receiver-operating curve analysis; the further addition of exercise seismocardiography contributes an additional $10 \%$ to the assessment accuracy in the diagnosis of anatomic CAD, a highly significant $(\mathrm{p}<0.00001)$ improve- ment. The inclusion of exercise seismocardiography with exercise electrocardiography and standard pretest data increases diagnostic accuracy to $85 \%$.

Effect of percent diameter stenosis criteria and extent of disease: The percent luminal diameter stenosis on coronary angiography was assessed qualitatively, and there are well-described limitations to the accuracy of this assessment. ${ }^{21,22}$ The sensitivity of the seismocardiogram and electrocardiogram did not change using either $\geq 50 \%$ or $\geq 70 \%$ diameter stenosis criteria; the sensitivity of the seismocardiogram was superior to that of the electrocardiogram at both stenosis criteria cutoffs. Thus, seismocardiography appears to provide an improved sensitivity without significant loss of specificity in patients with mild to moderate $\mathrm{CAD}$ using either a $\geq 50 \%$ or $\geq 70 \%$ stenosis criterion.

Seismocardiography appears to be equally sensitive in detecting anatomically significant $\mathrm{CAD}$ for single or Imultivessel disease. The absence of improvennent in sensitivity for the electrocardiogram between the single and multivessel disease categories is puzpling, but may be related to referral patterns to thallium-201 scintigraphy (and hence to angiography) in patients with suspect, negative exercise electrocardiograms. Patients with strongly positive, exercise electrocardiogram results may be referred directly to angiography and thus would not be included in our patient population.

Physiologically significant disease: The inaccuracies inherent in the use of qualitative assessment of percent stenosis by coronary arteriography for the diagnosis of CAD prompted use of alternative (i.e., physiologic) criteria. ${ }^{21}$ Thus, the requirements of $\geq 50 \%$ stenosis on angiography and a defect (fixed or reversible) on thallium scintigraphy would be expected to partially correct for the overestimation of disease based on $\geq 50 \%$ stenosis alone. ${ }^{22}$ Using these criteria for physiologically significant disease, seismocardiography was significantly more sensitive and also had a higher, but not statistically significant, negative predictive value compared with the electrocardiogram. Seismocardiographic specificity and positive predictive value were also well maintained using these criteria for physiologically significant disease.

Effect of concordance of seismocardiogram and electrocardiogram: Because both an electrocardiogram and seismocardiogram were obtained on the same exercise test, the diagnostic accuracy of concordant findings was assessed. Concordance, which occurred in $60 \%$ of patients, may contribute additional certainty to the exercise test conclusion, especially when both tests are negative.

Effect of gender: Sensitivity of the seismocardiogram was greater in both men and women, without a loss of specificity. Previous work found less specificity of the electrocardiographic stress test in women, ${ }^{23}$ but if allowance is made for the pretest prevalence of disease, it has been demonstrated that men and women have the same rate of false positives and negatives. ${ }^{24}$

Effect of medications: The sensitivity of the seismocardiogram was unaffected by either $\beta$-adrenergic blockers or calcium antagonists; it was greater than that 
of the electrocardiogram with or without either medication. The decreased sensitivity of the electrocardiogram compared with that of the seismocardiogram may be related to reduced exercise heart rate response or less myocardial ischemia. ${ }^{14}$

Effect of prior myocardial infarction: Seismocardiographic sensitivity was not significantly affected by the presence of prior myocardial infarction. In patients with or without prior infarction, the ST-segment response on the electrocardiogram was less sensitive than on the seismocardiogram. However, in practice, the presence of pathologic Q waves on the electrocardiogram would diagnose $\mathrm{CAD}$ even in the absence of ST changes on excrcise testing.

Effect of exercise heart rate: The seismocardiogram in contrast to the electrocardiogram did not show a loss of sensitivity in patients who exercised to $<85 \%$ of the age-predicted maximal heart rate. Seismocardiographic sensitivity was maintained even in patients who exercised to $<70 \%$ of the age-predicted maximal heart rate. Similar decrements in electrocardiographic sensitivity related to exercise heart rate $(<85 \%$ of age-predicted maximum) have been reported previously. 25

Effect of baseline ST depression: Resting ST depression on the baseline electrocardiogram was previously shown to decrease the specificity of the ST response with exercise. ${ }^{25}$ In the present study, the small number of patients $(n=3)$ with baseline ST depression and without anatomic CAD precludes conclusions concerning specificity.

Study limitations: Although this study shows an improvement in diagnostic accuracy for the seismocardiogram over the electrocardiogram, the data cannot be extrapolated to other groups of patients with bundle branch block or after cardiac surgery, because these patients were excluded from the study.

In this patient population, electrocardiographic sensitivity was low. This may be due in part to a referral bias of equivocal electrocardiographic stress tests to further evaluation by thallium stress testing and angiography. This referral bias would not have been imposed on the seismocardiogram, which was performed solely for the purpose of this study. The sensitivity of the electrocardiogram was greater in the physiologically significant and ischemic groups than in the anatomically significant group. The low sensitivity of the electrocardiogram may also be due to sampling variability. A large meta-analysis of exercise electrocardiograms for the diagnosis of CAD found an average sensitivity of $68 \%$ with a reportcd SD of $16 \% .^{1}$ The finding of $48 \%$ sensitivity for electrocardiography in the present study is within the range (23 to $100 \%$ ) reported in the aforementioned meta-analysis. Additionally, this same meta-analysis found the inclusion of equivocal exercise electrocardiographic results (usually inability to reach target heart rate) decreased sensitivity by $7.7 \%$. Our study protocol required classification of all exercise electrocardiographic results as positive or negative, and therefore, test results are included that would be classified as equivocal in actual practice. We considered using heart rate adjustment of ST-segment depression ${ }^{26}$ to improve the sensitivity of the electrocardiographic findings, but the approach remains controversial, 27,28 and the results vary among various investigators. ${ }^{29}$

Clinical implications: Exercise seismocardiography, performed in conjunction with exercise electrocardiography, has greater accuracy for diagnosing CAD than does exercise electrocardiographic testing alone, which is especially useful in groups such as women and patients receiving heart rate-limiting medications. The test is particularly suited to patients with intermediate pretest probabilities of $\mathrm{CAD}$, such as middle-aged women with typical or atypical angina, and middle-aged men with atypical angina. Application in clinical practice of the findings of a significant improvement in negative predictive accuracy for concordant results of exercise electrocardiograms and seismocardiograms can engender economic savings. A clinician gains more certainty with concordant negative test results, and therefore, there should be a reduction in the investigation of suspect negative exercise test results by more expensive procedures such as thallium-201 scintigraphy and coronary angiography. Additionally, the seismocardiograph itself is moderately priced $(\$ 18,500$ to $\$ 23,500)$. The simplicity of the seismocardiographic procedure, and the brevity of the recordings enable the clinician to easily incorporate exercise seismocardiography with standard exercise testing.

Acknowledgment: We gratefully acknowledge the assistance of Renée Mallett, RN, and Liviu Poliac, MD, the statistical assistance of Cynthia Morris, $\mathrm{PhD}$, and Laurie Fitch, MPH, and the excellent secretarial assistance of Mary Ann Studanski in the preparation of the manuscript. We thank George A. Diamond, MD, for review and suggested revisions of the manuscript.

\section{APPENDIX}

Study Coordinator: Renée C. Mallett, RN, Seismed Instruments Incorporated, Minneapolis, MN.

Angiograms: Scott W. Sharkey, MD, Candace D. Dick, MD, and David M. Salerno, MD, PhD, Hennepin County Medical Center, Minneapolis, MN.

Electrocardiograms: Kyuhyun Wang, MD, Steven R. Goldsmith, MD, and David M. Salerno, MD, PhD, Hennepin County Medical Center, Minneapolis, MN.

Thalliums (site readers): David D. Stuart, MD, Hennepin County Medical Center, Minneapolis, MN, and Anthony M. Cook, MD, Abbott-Northwestern Hospital.

Seismocardiograms: John M. Zanetti, MS, and Mark D. Winston, BA, Seismed Instruments Incorporated, Minneapolis, MN, and Richard S. Crow, MD, University of Minnesota, Minneapolis, MN.

\section{REFERENCES}

1. Gianrossi R, Detrano R, Mulvihill D, Lehmann K, Dubach P, Columbo A, McArthur D, Froelicher V. Exercise-induced ST depression in the diagnosis of coronary artery disease. A meta-analysis. Circulation 1989;80:87-98.

2. Goldschlager N, Sox HC, Jr. The diagnostic and prognostic value of the treadmill exercise test in the evaluation of chest pain, in patients with recent myocardial infarction, and in asymptomatic individuals. Am Heart $J$ 1988;116:523-535. 3. Ritchie IL, Zaret BL, Strauss HW, Pitt B, Benram DS, Scheltert HR, Ashbun WL, Berger HJ, Hamilton GW. Myocardial imaging with thallium-201: a multicenter study in patients with angina pectoris or acute myocardial infarction. Am J Cardiol 1978;42:345-350. 
4. Jones RH, McEwan P, Newman GE, Port S, Rerych SK, Scholz PM, Upton MT, Peter CA, Austin EH, Leong K-H, Gibbons RJ, Cobb FR, Coleman RE, Sabiston $\mathrm{DC}$. Accuracy of diagnosis of coronary artery disease by radionuclide measurement of left ventricular function during rest and exercise. Circulation $1981 ; 64: 586-601$.

5. Presti $\mathrm{CF}$, Armstrong WT, Feigenbaum II. Comparison of echocardiography at peak exercise and after bicycle exercise in evaluation of patients with known or suspected coronary artery disease. I Am Soc Echo 1988;1:119-126.

6. Salerno DM, 7anetti I. Seismocardingraphy—a new technique for recording cardiac vibrations: concept, method and initial observations. I Cardiovasc Technol 1990;9:111-118.

7. Salerno DM, Zanetti JM, Green LA, Mooney MR, Madison JD, Van Tassel RA. Seismocardiographic changes associated with obstruction of coronary blood flow during balloon angioplasty. Am J Cardiol 1991;68:201-207.

8. Silvestre A, Sandhu G, Desser KB, Benchimol A. Slow filling period/rapid filling period ratio in the apexcardiogram: relation to the diagnosis of coronary artery disease. Am J Cardiol 1978;42:377-382.

9. Grandi A, Barzizza F, Bernardi L, Venco A, Finardi G. Kinetocardiographic detection of ventricular dyssynergy after myocardial infarction. Acta Cardiol 1984:39:19-27.

10. Taymor RC, Pordy L, Chesky K, Moser M, Master AM. The ballistocardiogram in coronary artery disease. JAMA 1952;148:419-423.

11. Scarborough WR, Mason RE, Davis FW, Singewald ML, Baker BM, Lore SA A ballistocardiographic and electrocardiographic study of 328 patients with coronary artery disease: comparison with results from a similar study of apparently normal persons. Am Heart J 1952;44:645-6/0.

12. Silverberg RA, Diamond GA, Vas R, Tzivoni D, Swan HJC, Forrester JS Noninvasive diagnosis of coronary artery disease: the cardiokymographic stress test. Circulation 1980;51:570-589.

13. Weiner DA, and Principal Investigators. Accuracy of cardiokymography during exercise testing: results of a multicenter study. $J$ Am Coll Cardiol 1985;6:502509 .

14. Sheffield LT. Exercise stress testing. In: Braunwald E, ed. Heart Disease: A Textbook of Cardiovascular Medicine. Philadelphia: WB Saunders, 1988:228-232. 15. Salemo DM, Zanetti JM, Poliac LC, Crow RS, Hannan PJ, Wang K, Goldenberg IF, Van Tassel RA. Exercise seismocardiography for detection of coronary artery disease. Am J Noninvasive Cardiol 1992;6:321-330.

16. Gordon T, Sorlie P, Kannel WB. Coronary heart disease, atherothrombotic brain infarction, intermittent claudication. A multivariate analysis of some factors related to their incidence: Framingham Study, 16-year follow-up. In: Kannel WB, Gordon T, eds. The Framingham Study. An Epidemiologic Investigation of Cardiovascular Disease. Washington, D.C.: US Government Printing Office, 1971.

17. Diamond GA, Forrester JS. Analysis of probability as an aid in the clinical diagnosis of coronary-antery disease. N Engl J Med 1979;300:1350-1357.

18. Blackburn HB, Luepker RV, Kline FG, Bracht N, Carlaw R, Jacobs D, Mittelmark M, Stauffer L, Tayor HL. The Minnesota Heart Health Program: a research and demonstration project in cardiovascular disease prevention. In: Matarazzo JD, Weiss SM, Herd JA, Miller NE, eds. Behavioral Health. A Handbook of Health Enhancement and Disease Prevention. New York: John Wiley, 1984.

19. Hanley JA, McNeil BJ. The meaning and use of the area under a receiver operating characteristic (ROC) curve. Radiology 1982;143:29-36

20. Diamond GA. ROC steady: a receiver operating characteristic curve which is invariant relative to relocation bias. Med Decis Making 1987;7:238-243.

21. Marcus ML, White CW, Kirchner PT. Isn't it time to reevaluate the sensitivity of noninvasive approaches for the diagnosis of coronary artery disease? $\mathrm{J} \mathrm{Am}$ Coll Cardiol 1986;8:1033-1034.

22. Fleming RM, Kirkeeide RL, Smalling RW, Gould KL. Pattems of visual interpretation of coronary arteriograms as detected by quantitative coronary arteriography. J Am Coll Cardiol 1991;18:945-951.

23. Sketch MH, Mohiuddin SM, Lynch JD, Zencka AE, Runco V. Significant sex difference in the correlation of electrocardiographic exercise testing and coronary arteriograms. Am J Cardiol 1975;36:169-173.

24. Weiner DA, Ryan TJ, McCabe CH, Kennedy JW, Schloss M, Tristani F, Chaitman B, Fïsher $\mathbf{L}$. Exercise stress testing: correlations among history of angina, ST segment response, and prevalence of coronary artery disease in the Coronary Artery Surgery Study (CASS). N Engl J Med 1979;301:230-235.

25. Fortuin NJ, Weiss JL. Exercise stress testing. Circulation 1977;56:699-712.

26. Kligfield $P$, Ameisen $O$, Okin PM. Heart rate adjustment of $S T$ segment depression for improved detection of coronary artery disease. Circulation 1989;79:245-255. 27. Lachterman B, Lehmann KG, Detrano R, Nente] I, Froelicher VF. Comparison of ST segment/heart rate index to standard ST criteria for analysis of exercise electrocardiogram. Circulation 1990;82:44-50.

28. Kligfield $\mathrm{P}$, Okin PM. The academic life of a noninvasive test. Circulation 1990;82:2284-2285.

29. Bobbio $M$, Detrano $R$. A lesson from the controversy about heart rate adjustment of ST segment depression. Circulation 1991;84:1410-1413. 